\title{
Pensamiento filosófico latinoamericano: humanismo, método e historia*
}

\author{
Latin American philosophical thinking: \\ humanism, method and history \\ Pensamento filosófico latino-americano: \\ humanismo, método e história
}

Fecha de entrega: 15 de diciembre de 2013

Fecha de aprobación: 13 de junio de 2014

Damián Pachón Soto ${ }^{* *}$

El filósofo cubano Pablo Guadarrama entrega en este libro una especie de suma de sus más de 30 años de estudio, análisis, difusión y defensa del pensamiento latinoamericano. No ha sido una labor fácil, como él mismo lo ha reconocido, pues ha tenido que enfrentarse y confrontarse con quienes han pensado que la nuestra no es auténtica filosofía, como si el logos fuera patrimonio de Europa o de algún pueblo en especial y no más bien de aquello que nos constituye específicamente como hombres. Por eso, en estos tomos se inicia reflexionando sobre aspectos epistemológicos y metodológicos, tal como lo anuncia el subtítulo de la obra. Aquí el eje del pensamiento de Guadarrama es el tema del humanismo, una constante en su labor filosófica. Guadarrama ha estado convencido de que el hombre, a pesar de

* Guadarrama González, P. (2012-2013) Pensamiento filosófico latinoamericano: humanismo, método e historia (Vol. 1-3). Bogotá: Planeta, Universidad Católica de Colombia y Universitá Degli Studi de Salerno. X p. ISBN: $x x x$.

** Docente de la Facultad de Filosofía y Letras de la Universidad Santo Tomás. Correo electrónico: damianpachon@gmail.com 
sus retrocesos, busca una constante perfectibilidad y esto es notorio en los logros emancipatorios que ha logrado en la historia. Eso es innegable. Por eso, su postura es optimista, de confianza en las potencialidades transformadoras del ser humano, en su poder para autoproducirse, producir, reproducir, pero también de crear nuevas condiciones de existencia.

El capítulo segundo del primer tomo está dedicado a interesantes problemas que han ocupado a la inteligencia americana, por usar aquí la expresión del gran Alfonso Reyes, entre ellos, el de la originalidad y autenticidad del pensamiento. En este sentido, Guadarrama sostiene que un pensamiento es tal cuando las ideas que expresa "[...] se han correspondido con las exigencias históricas de su momento en los diferentes planos, esto es, sociopolítico, económico, ideológico, científico”. Esto se ha hecho a partir del pensamiento que se ha producido en esta región y en la "apropiación creadora" que se ha realizado de las ideas formuladas en otras latitudes. Asimismo, al plantearse el problema de la identidad, el autor supera esa manía posmoderna de reducir tal concepto a una esencia fija solo con el prurito de mostrarse originales frente a lo que Nietzsche llamó los conceptos-momia de la filosofía tradicional. En este caso, Guadarrama muestra una visión dinámica de la llamada identidad latinoamericana, que es "[...] histórica y concreta, no ha sido dada de una vez por todas" (2012-2013, p. 105) y no ha borrado precisamente las diferencias contenidas en nuestra reconocida diversidad. El resto del primer tomo se ocupa del humanismo y de la manera en que el problema de la alienación-desalienación se ha abordado en las obras que hacen parte del pensamiento latinoamericano, partiendo desde lo amerindio hasta llegar a su coterráneo José Martí.

El segundo tomo sigue un derrotero cronológico. Estudia el positivismo en América Latina y autores como Enrique José Varona, José Ingenieros, José Enrique Rodó, José Vasconcelos, Antonio Caso, Henríquez Ureña, Alejandro Korn, Francisco Romero, Fernando Ortiz y nuestro autor colombiano Luis Eduardo Nieto Arteta. Hay que decir, que el propósito de Guadarrama no es meramente historiográfico, pues al final del tomo nos invita a "[p]ensar con cabeza propia" (2012-2013).

Finalmente, el tercer tomo se ocupa del siglo XX. Inicia describiendo el legado de José Gaos, pasa por el estudio de la obra de Leopoldo Zea, Arturo Andrés Roig, de la filosofía en Cuba y Puerto Rico y termina con un rico panorama de lo que han sido las ideas socialistas y marxistas en el continente. Como puede verse, este es un libro que no puede quedar en los anaqueles ni es diferente de las mejores producciones 
historiográficas y reflexivas que se han escrito sobre la filosofía en América Latina. Por eso, termino esta reseña con palabras que hacen parte de un ensayo realizado en homenaje de Guadarrama, que se publicará próximamente y que se titula "Pablo Guadarrama y la filosofía colombiana: un testimonio":

Guadarrama González puede ser considerado —en el caso colombiano- como uno de los normalizadores de nuestra filosofía, de su enseñanza y conocimiento en Colombia. Ha desempeñado este lugar no solo por difundir el pensamiento del resto de nuestra América, sino porque a pesar de ser cubano no ha escatimado esfuerzos por investigar el pensamiento nuestro, así lo prueban sus escritos sobre Antonio García, Jorge Eliécer Gaitán, Darío Botero, entre otros. Son estas las razones por las cuales Pablo Guadarrama ocupa un lugar especial en el corazón de quien esto escribe y en nuestra historia intelectual colombiana. 